\title{
Framing Faculty and Student Discrepancies in Engineering Ethics Education Delivery
}

\author{
Matthew A. Holsapple, Donald D. Carpentera ${ }^{\mathrm{a}}$ Janel A. SutKus ${ }^{\mathrm{b}}$, \\ CyNTHia J. Finelli, AND TREVOR S. HARDing ${ }^{c}$ \\ University of Michigan, Lawrence Technological University ${ }^{\text {a }}$, Carnegie Mellon \\ University ${ }^{\mathrm{b}}$ California Polytechnic University ${ }^{\mathrm{c}}$
}

\section{BACKGROUND}

The importance of ethics education in professional engineering preparation programs is well established, yet student outcomes remain mixed despite the efforts of engineering educators.

\section{Purpose (Hypothesis)}

A long line of research has suggested that students and faculty often have different perceptions of educational efforts and practices. In this study, we consider this as a potential reason for the continued mixed results of engineering ethics education by examining differing perceptions of faculty and students about ethics education and identifying contributing factors to those differences.

\section{DESIGN/MeTHOD}

We conducted focus groups and interviews with engineering undergraduate students, faculty, and administrators on 18 campuses. Transcripts were analyzed using both deductive and inductive analyses and constant comparison. We identified both themes of discrepancies between faculty/administrator and student perceptions and factors in the educational environment that contributed to those discrepancies.

\section{RESULTS}

Discrepancies between the perceptions of faculty/administrators were seen in two forms. Faculty/ administrators believed that ethics education encompasses teaching about laws, ethical codes, and other black-and-white solutions while also addressing more nuanced ethical dilemmas; students reported only experiencing the laws-and-rules approach. Students also did not see faculty as the positive ethical role models that faculty believed they are. Factors that contribute to both types of discrepancies are identified and reported.

\section{ConClusions}

This approach can be effective in examining difficulties in teaching engineering ethics. Educators should take steps to understand the different ways faculty/administrators and students perceive ethics education, and how factors in the educational environment contribute to differences in those perceptions.

\section{KEYWORDS}

culture, environment, ethics

\section{INTRODUCTION}

Recent, high profile cases such as the Gulf of Mexico oil spill and deadly automobile steering and braking failures, as well as increasing emphases on issues of sustainability and globalism, have brought national and international attention to ethical engineering practice. Multiple national reports have called for increased focus on high ethical standards for 
future engineers and the need for colleges and universities to provide students with effective professional engineering ethics education (ABET, 2010; National Academy of Engineering (NAE), 2003, 2004). Sheppard, Macatangay, Colby, and Sullivan (2009) argue that as technology grows more complex and its effects on the world become harder to predict, the ethical issues faced by engineers also grow in complexity and uncertainty. However, they call the preparation for students to develop a solid understanding of the impacts of their work on "environmental protection, safety, and the broad human impact of engineering work" the "least realized, most outsourced, and least connected" (p. 136) component of the prevalent method of engineering education.

Professional engineers have reported that their ethics education as undergraduates did little to prepare them for the ethical realities they face in their profession (McGinn, 2003). Similar concerns have been expressed by the NAE (2003) that students are not being well educated to understand the potential "social and ethical implications" of employing their technical skills, and Colby and Sullivan (2008) found engineering programs to be "spotty and unsystematic" (p. 332) in their teaching of professional ethics and uncertain in ways of assessing student outcomes. Although the field of engineering is in agreement about the importance of ethics education, current methods of education may not be adequate to prepare students with necessary ethical competencies (Haws, 2001; Newberry, 2004).

One reason for the gap between the importance of the ethics education and the realities of the curriculum may be that students are not experiencing engineering ethics education in the manner that faculty feel they are delivering it. Higher education research has demonstrated that students and faculty often have discrepant perceptions of the content and effectiveness of instruction. For example, there have been shown to be large differences between the perceptions of student and faculty of the value and effectiveness of learning assessments (MacLellan, 2001), the definition of what counts as student classroom participation (Fritschner, 2000), and the desirable qualities in lecturers and discussion section leaders (Goldstein \& Benassi, 2006). In some cases, these differences were even found when students and faculty had the same objective experiences; these discrepancies were found in regards to teaching and instructor performance (Miron, 1988; Nasser \& Fresko, 2006; Wachtel, 1998), the amount of feedback students received (Gill, Heins, Jones, 1984), and quality of participation by specific students (Fritschner, 2000).

In this paper, we explore the potential of these discrepancies between faculty and student perceptions as a way of understanding difficulties in ethics education in professional engineering programs, specifically considering differences in the goals and perceptions of engineering faculty and administrators and the experience of the students. We are particularly examining the gap between the recognized need for results of professional engineering ethics education and the ability of higher education to deliver that education by investigating two research questions:

1. In what ways do the faculty and administrator perceptions of ethics education at their institutions differ from the experience of the institutions' students?

2. How might students' experiences in the broader educational environment contribute to those discrepant perceptions?

\section{COMPREHENSIVE Model of StUdent ETHicAL DEVELoPMENT}

This paper relies on a conceptual framework of a student's ethical development during college that we developed and which informed the design of research questions, analysis of data, and interpretation of results. This framework of ethical development was developed 
from the tradition of Astin's Inputs-Environments-Outputs (I-E-O) model (Astin, 1970a, 1970b, 1993). Astin's model, which has long served as the dominant framework for studying college student outcomes, conceives of these outcomes as arising from students' precollege characteristics and their experiences within their institution's specific environment. Terenzini and Reason (2005) expanded upon Astin's I-E-O model to provide more detail on the ways that environments act upon students, including aspects of organizational context and curricular and co-curricular experiences. We have adapted the model to apply to students - and in this paper specifically to engineering students - across their entire college experience as a framework for analyzing data collected and drawing conclusions from the larger investigation of engineering ethics education.

Our conceptual framework of a student's ethical development during college (see Figure 1) conceives of distinct, yet interrelated, domains affecting students' engineering ethical development: Student Characteristics, Institutional Culture (comprising both organizational context and peer environment), and Individual Student Experiences (including Formal Curricular Experiences and Co-curricular Experiences).

Student Characteristics refers to student demographic and behavioral characteristics, including sociodemographic characteristics, high school behaviors, academic major, and academic achievement. Institutional Culture refers to the culture of the engineering school or department within the context of the institution as a whole, both of which influence student outcomes. Following Terenzini and Reason's model (2005), we separate Institutional Culture into two constructs: the Organizational Context (representing formal organizational structures; academic and institutional priorities, mission, and ethos; and faculty culture) and the Peer Environment (representing not only aggregated student characteristics, but also the dominant values, attitudes, beliefs, and behaviors of the student body). The Peer Environment also consists of numerous individual students which the model includes as Individual Student Experiences. This acknowledges that despite a shared peer environment with the institutional culture, the individual experiences of students within that culture can vary widely. Included in those individual experiences are students' Formal Curricular Experiences (including both the classes taken and the type of instruction in

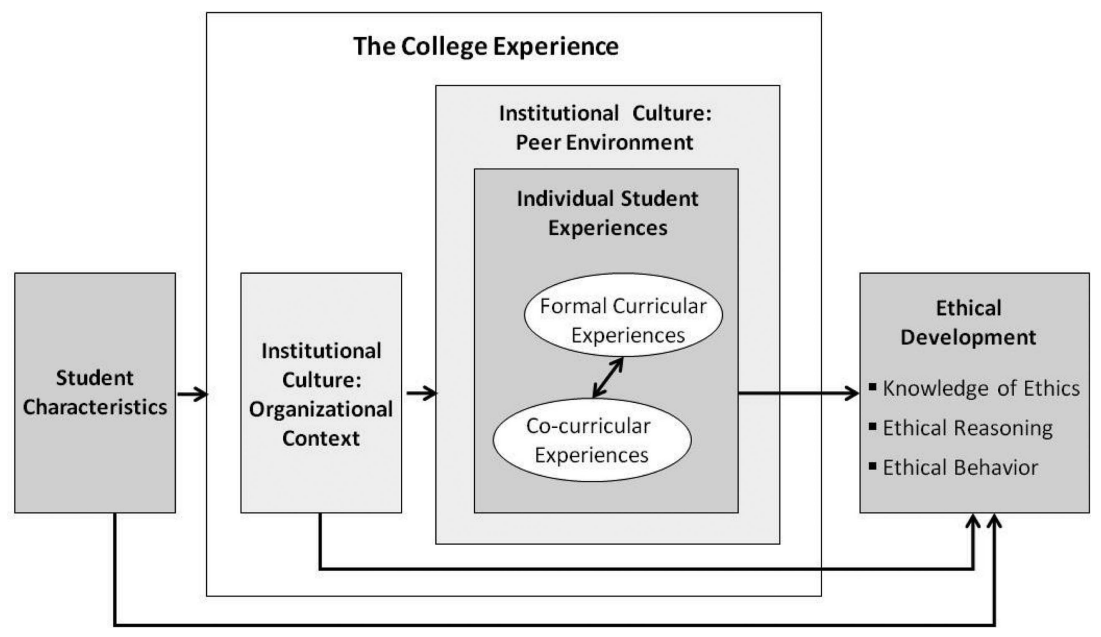

FIGURE 1. Conceptual framework of a student's ethical development during college 
those classes) and Co-curricular Experiences (for example, participation in student organizations and internships).

Finally, the model considers students' engineering Ethical Development as comprising three distinct constructs: knowledge of ethics, ethical reasoning, and ethical behavior. Knowledge of Ethics refers to a student's understanding of professional engineering codes of ethics and other rules governing ethical behavior; Ethical Reasoning refers to a student's ability to apply reason when identifying ethical options to ethical dilemmas, and Ethical Behavior refers to the extent to which students engage in behaviors consistent with their reasoned ethical decisions.

In the years since Terenzini and Reason introduced the model, they have demonstrated the utility of the model for addressing outcomes including academic competence (Reason, Terenzini, \& Domingo, 2006), social and personal competence (Reason, Terenzini, \& Domingo, 2007), interaction with difference (Reason, Cox, Quaye, \& Terenzini, 2010) and persistence (Reason, 2009). Other researchers have used the model to study a range of outcomes in a range of contexts, including sense of community and retention of first-year students in science, technology, engineering, and mathematics students (Falls, 2009); ethical development in engineering students (Bielby et al., 2011; Burt et al., 2011; Holsapple et al., 2011); spiritual development of first-year students (Lovik \& Volkwein, 2010); the effects of part-time faculty on first-year students (Eagan \& Jaeger, 2008; Jaeger \& Hinz, 2008); theological development in seminary students (Lincoln, 2009); and a range of outcomes, including engaging in civic and campus life and cultural competence, for students living in residence halls (Murphy, 2010).

\section{MeTHODS}

\section{Participants and Data}

This study uses an ex post facto design; data used in this study were collected as part of a larger study of engineering ethics education that was guided by a broader research question (What is the impact of educational experiences and institutional culture in students' ethical development?). Consequently, we developed focus group and interview protocols that did not specifically ask questions addressed in this paper. However, because these data include the perspectives of a large number of students, faculty, and administrators about their experiences with the full range of engineering ethics education at their institutions, they were well-suited to address the research questions posed in this paper. Over the course of three years (2007-2009), we conducted focus groups with engineering faculty and students and personal interviews with senior-level academic and student affairs administrators at the engineering schools or departments of 18 colleges and universities. Partner institutions were selected based on large enrollment in traditional engineering disciplines (mechanical, electrical, and civil engineering), diversity of student populations, geographic location, and to represent a wide range of institution Carnegie classification (Carnegie Foundation for the Advancement of Teaching, 2009).

We collected data from three populations: undergraduate engineering students, engineering faculty, and senior-level administrators. These populations were chosen based on the differing perspectives that each would have on students' ethical development. Students were randomly selected for invitation, and faculty were recruited based on their familiarity with their institution's ethics education practices and students' ethical development. Administrators were recruited who oversaw aspects of undergraduate education and undergraduate 
TABLE 1

Demographic Characteristics of Participants in Student and Faculty Focus Groups

\begin{tabular}{|c|c|c|c|c|}
\hline & $\begin{array}{l}\text { Students } \\
(\mathrm{n}=123)\end{array}$ & $\begin{array}{l}\text { Students } \\
\text { Proportion }\end{array}$ & $\begin{array}{l}\text { Faculty } \\
(\mathrm{n}=110)\end{array}$ & $\begin{array}{c}\text { Faculty } \\
\text { Proportion }\end{array}$ \\
\hline Male & 84 & 0.683 & 93 & 0.845 \\
\hline Female & 39 & 0.317 & 18 & 0.164 \\
\hline American Indian or Alaskan Native* & 1 & 0.008 & 2 & 0.018 \\
\hline Asian* & 11 & 0.089 & 11 & 0.100 \\
\hline Black or African American* & 17 & 0.138 & 2 & 0.018 \\
\hline $\begin{array}{l}\text { Native Hawaiian or Other Pacific } \\
\text { Islander* }\end{array}$ & 1 & 0.008 & 0 & 0.000 \\
\hline White* & 93 & 0.756 & 100 & 0.909 \\
\hline Hispanic* & 5 & 0.041 & 5 & 0.045 \\
\hline Freshman & 26 & 0.211 & - & \\
\hline Sophomore & 24 & 0.195 & - & \\
\hline Junior & 25 & 0.203 & - & \\
\hline Senior & 48 & 0.390 & - & \\
\hline Tenured & - & & 62 & 0.564 \\
\hline Non-Tenured, but Tenure Track & - & & 22 & 0.200 \\
\hline Not on Tenure Track & - & & 26 & 0.236 \\
\hline $\begin{array}{l}\text { Very High Research Institutions } \\
(\mathrm{n}=5)\end{array}$ & 30 & 0.244 & 32 & 0.291 \\
\hline High Research Institutions $(n=5)$ & 28 & 0.228 & 30 & 0.273 \\
\hline Master's Institutions $(n=4)$ & 34 & 0.276 & 26 & 0.236 \\
\hline $\begin{array}{l}\text { Baccalaureate and Specialty } \\
\text { Institutions** }(n=4)\end{array}$ & 31 & 0.252 & 23 & 0.209 \\
\hline
\end{tabular}

Note. ${ }^{*}$ Responses in the race categories may not match the total number of participants. Our demographic assessment instructs respondents to select all categories that apply, so respondents identifying as multiracial may select more than one category. In addition, some respondents did not respond to this item. ** Because of the small numbers of institutions in each category nationally, baccalaureate institutions and specialty institutions have been combined to protect the anonymity of participating individuals and institutions.

student affairs; titles of interviewed administrators included dean of the college of engineering, associate dean for undergraduate programs, and dean of students.

This selection yielded a sample of 123 students and 110 faculty members. They participated in a total of 36 student- or faculty-specific focus groups - one for each group at each of the 18 partner institutions. Protocols for the 90-minute focus groups and interviews included two parts: in each, participants discussed elements of the institutional culture that 
they saw as affecting students' ethical development as well as (1) the ways that ethics was incorporated into the students' experiences or (2) the ways that students identified and approached ethical dilemmas (for more information on protocol development, see Finelli et al., in press; Holsapple, Finelli, Carpenter, Harding, \& Sutkus, 2009; Sutkus, Carpenter, Finelli, \& Harding, 2008). The majority of participants in both the student and faculty focus group were male and White. However, senior students and tenured professors were over-represented in their respective groups. Furthermore, females were in general overrepresented as compared to national averages in engineering. See Table 1 for more detailed demographic information about focus group participants.

In addition to these focus groups, we also conducted 60-minute interviews with a total of 36 administrators, two on each campus. Because of the small number of administrators interviewed on each campus, potentially identifiable demographic characteristics were not collected for these participants in order to protect confidentiality.

\section{Analysis}

Analysis for this study followed a process that combined both deductive and inductive analyses, similar the approach recommended by Patton (2002) and previously applied to engineering education research by Turns, Eliot, Neal, and Linse (2007). Data were first reduced and then deductive analysis was applied to view through the lens of our conceptual framework of a student's ethical development during college and the assumption that discrepancies between student and faculty perceptions did exist. We then used inductive analysis to identify patterns specific to our data. First, we analyzed transcripts from each focus group and interview, reducing the data to that which applied to our research questions. To do so, all portions of the transcripts were selected that discussed curricular ethics education, as referring to its necessity, implementation, and/or efficacy. Using an inductive approach, those data were then open-coded (Corbin \& Strauss, 2008) to identify themes in the way ethics education was discussed among the three participant groups. This analysis was repeated for transcripts from all 18 institutions.

To answer the first research question (In what ways do the faculty and administratorperceptions of ethics education at their institutions differ from the experience of the institutions' students?) we used deductive analysis to look for differences in the codes and themes between faculty/administrators and students. Comparisons were made for each campus to identify campus-specific discrepancies between the way that faculty/administrators and students discussed these aspects of ethics education. When differences emerged, those that showed discrepancies between the goals and perceptions of faculty and administrators of ethics education in practice and the experiences of students at the same institution were noted. Finally, we compared institutional themes to identify themes of discrepancies that applied across the sample of institutions. For the entire coding process, we analyzed transcripts using a constant comparative process (Corbin \& Strauss, 2008; Merriam, 1998), so that when new themes emerged from the data, previously-coded data were reanalyzed to look for those new themes. This type of analysis allows researchers to continually reconsider data from new perspectives.

To answer the second research question (How might students' experiences in the broader educational environment contribute to those discrepant perceptions?), the reduced data were reanalyzed. This time we used deductive coding first, and the discussions of the need, implementation, and efficacy of ethics education were coded for descriptions of aspects of the students' experiences that might contribute to the discrepancies found in the first phase of analysis. We identified these contributing factors based on fulfilling one of three criteria: 
(1) it was discussed at the same time as an aspect of the discrepancy, (2) a participant explicitly connected the experiences with the discrepancy, and (3) we, as researchers, determined that the two were connected based on understanding of the data collected at the institution. Then, we returned to inductive analysis and data that had been coded as referring to those contributing factors were recoded using an open-coding process, so that themes emerged from the data without predetermination. Those emergent themes were consolidated within each institution, and then institutional comparisons were made to determine the extent to which they applied across the sample.

\section{RESULTS}

For both research questions, the themes discussed were chosen for two reasons: (1) they were consistent across institutions, and (2) they had a powerful ability to illustrate the existence of discrepancies in student and faculty perceptions and their contributing factors as a way of examining ethics education. Each of the themes discussed was identified in at least one-third of the institutions in the sample and within at least three of the four institution types.

This study's first research question (In what ways do the faculty and administrator perceptions of ethics education at their institutions differ from the experience of the institutions' students?) investigates the ways that faculty and administrators' goals for and perceptions of ethics education at their institutions differ from the experience of the institutions' students. Two such discrepancies emerged from the data:

1. Faculty describe ethics education as including nuanced treatment of complex issues, but students report hearing simplistic, black-and-white messages about ethics.

2. Faculty and administrators see themselves as providing messages of engineering ethics education by the way they model ethical behaviors. Students, however, report that in many cases they don't learn ethics by observing faculty.

In this section, we discuss both discrepancies in detail. For each discrepancy, we also address the second research question (How might students' experiences in their instructional and educational context contribute to those discrepant perceptions?) by outlining emergent themes of factors students, faculty, and administrators describe which contribute to these discrepancies. Quotations from participants represent a sample of the commonly identified themes. A thorough investigation of the ways that these results may differ by institution type is beyond the scope of this study; however we include the classification of the institution for each quotation to provide additional context.

\section{Discrepancy 1: Right and Wrong (I.E. Black-AND-White) Versus CompleX APPROACHES}

The first theme of discrepancies between the perceptions of faculty, administrators, and students is the difference in what these groups considered to be the focus of the professional engineering ethics curriculum. Faculty and administrators reported that they attempt to balance the need for students to understand and follow professional codes of ethics, legal requirements, and other guidelines with the desire to teach students to think critically and carefully about complex ethical dilemmas and develop their own ethical and moral standards. Students, however, reported that the education they received focused almost exclusively on black-and-white, rules-based interpretations of ethics, ignoring more nuanced issues and "gray areas." 
One faculty member, for example, stressed that although students need to understand the professional codes of ethics and how engineering works within a legal framework, they also need to be taught to move beyond code-based and legal perspectives to a more holistic approach that integrates the needs of the public and the student's own ideas about ethics and morality. This faculty member at a very high research institution stated:

The problem that I see students facing is that we have such a litigious society and many things that are legally correct but ethically wrong from a professional point of view. And this has to be brought out, that you need to do what's right for the public, not necessarily what the law might say. So they have all these dilemmas that they run into and to lead them through it and let them develop their own mentality that this is, you have to be conscious of your responsibility as a professional that you are there to protect the health and safety of the people in whatever you do.

Faculty also acknowledged the appeal to students of a focus on ethical reasoning and ethical behavior. At one institution, faculty talked about their efforts to incorporate more complex considerations of ethics alongside learning the engineering codes of ethics and academic integrity issues. One faculty member at a high research institution said:

I do notice that the students get a lot more engaged when we start talking about ethical issues, not just in the traditional engineering sense, like I'm not going to copy off of somebody or I'm not going to steal somebody's ideas and, you know, steal tens of millions of dollars of ideas and take them to China or something like that. But when you start talking about real people's lives and the difference that you can make in them, they do get really engaged in that.

For another faculty member at a high research institution, an approach to ethics education that focuses on reasoning rather than simply memorizing ethical knowledge is an extension of the teaching of engineering in general. As a field that relies heavily on problemsolving and analytical thought, engineering programs help students to take that same approach to ethical dilemmas:

What we can do in engineering is teach a thought process. Rather than, "How do we get the answer?" have the students ask the questions, "How is this going to impact others? What is the follow-on project? What's the impact on nature?" and so on. Some of the courses...we can tell them there are different ways of looking at it; you'll get different answers depending on the question you ask.

Many faculty members discussed the need to balance the knowledge of ethics in professional engineering ethics education with the inclusion of ethical reasoning and ethical behavior, but students at these campuses described professional ethics education in engineering classes as focusing primarily on adherence to codes of professional ethics and avoiding the punishments and negative personal consequences that can arise from unethical decisions and actions. In some cases, students expressed frustration that their ethics education had not included these more nuanced and "bigger picture" ethical problems, which they saw as valuable to their professional preparation as ethical engineers.

For example, students said that their ethics education was almost solely focused on academic integrity and warnings not to cheat on coursework; it did not include 
discussion of complex ethical dilemmas that engineers face. A student in bioengineering at a very high research institution said:

I think bioengineering, like the ethics kinda go beyond just cheating or faking data. I mean, you have to deal with animal testing or, you know, stem cells. Like, is that ethical?

In general, students saw that the ethical dilemmas that confront engineers and the decisions that they make affect whole communities and societies. They wished that ethics education would focus more on the ethical reasoning needed to think about and balance those potential impacts. One student at another very high research institution said:

I think the university could do a lot to promote ethics and they already do a lot but I think they could kinda broaden what they do ... If, I think, the university concentrates less on promoting ethics in specific examples like cheating on a test, and more in a broad way like, exposing students to more things, increasing awareness of something important to society you know, then you can promote ethics.

A student in the same focus group agreed, saying:

[Professional ethics] is really not addressed very much, and so it's easy for engineers to just be in like a little bubble - 'T'm doing this formula, solving this equation' - but they don't really talk about engineers' influence on society and, like, corporate social responsibility and things like that, which are important for all engineers.

Contributing factor: Academic integrity and student punishment. In focus groups and interviews, all three types of participants discussed the focus on academic integrity issues and the use of punishment and other negative personal consequences to deter unethical behavior. They discussed the teaching of academic integrity as a clear-cut issue, in which students are taught to follow rules in order to avoid consequences. This focus on academic integrity and not cheating in ethics instruction crowds out messages about more nuanced ethical decision-making in the professional context. A successful focus on academic integrity and combating student cheating is not inappropriate; the problem is that students describe that they see this as the singular focus of their ethics education and other important topics are secondary or are left out completely. For example, a student at a very high research university expressed frustration at the focus solely on academic integrity and cheating rather than on ethical issues in engineering, saying:

I think that the university should or could talk about ethics more on a bigger scale than just like cheating on your homework, because I think it would be better for them to emphasize ethics in terms of your responsibilities as an engineer, what role you have occurring there.

A fifth-year student at a high research institution stated that ethics instruction during the first year had incorporated professional ethics issues, but beyond that almost all attention paid to ethics was to caution students not engage in specific types of academic cheating. The student said:

Beyond the freshman engineering courses that all engineers have to take, I really had very little ethics, specifically ethical reasoning training or experience in these situations just developing the ability to recognize an ethical problem. Beyond that first class, the only kind of ethics that we encounter is academic ethics, you know 
integrity and not copying other people's work, plagiarism, and other than that I had no experience.

A professor at a very high research institution had concerns that the messages being sent about academic integrity were too focused on the consequences and potential punishments students could face rather than a more nuanced discussion of academic integrity as a complex ethical issue. This faculty member reported struggling with the way to present academic ethics information in class so that the emphasis on punishment and consequences was limited, saying:

My syllabus has a really lengthy discussion on the consequences of academic dishonesty and the importance of it. And basically the university has a policy that you can refer to and talk about the consequences and [how] one bad decision can have a long-lasting impact. But I'm still struggling to find a better way, rather than threatening them, to get them to appreciate the importance, but I just can't come up with a better solution other than just sort of describing the worst case scenario and sort of motivating them to be honest.

The common approach to academic ethics described is one that focuses on punishment and negative consequences to students if they do not follow a set of rules about academic integrity. While educating students to avoid cheating in academic coursework is important, this focus on one issue-and the simplistic treatment of it-is seen by participants as taking the place of more complex discussions of ethics encountered in engineering.

\section{Discrepancy 2: Role-Modeling Positive Ethical BeHavior}

Faculty and administrators spoke often about the benefit to students' ethics education of observing the ethical behavior of the faculty themselves; they saw the faculty as rolemodeling positive ethical behaviors for the students. Students, on the other hand, largely did not consider the faculty to be role models for ethical behavior (or saw them as negative role models) and did not perceive this role-modeling to be a component of their ethics education. This theme appeared across institution types and was not limited to large institutions with high student-to-faculty ratios.

One faculty member at a very high research institution summarized the belief that professors serve as effective ethical role models, saying,

I think that setting that example is very important. It's setting an expectation; it's saying, "I believe in this." So, yes, I think the faculty do affect student behavior ... They are, in some sense, the role models that students see.

Other faculty echoed that sentiment, sometimes outlining ways that faculty modeled specific behaviors from which students learn. A faculty member at a baccalaureate or specialty institution said that the collegial way in which faculty interacted was one way that ethics was taught. The professor said,

I'll say that, to a large extent, we teach [ethics] by example, even without having to lecture, [with] the effort we make to treat each other with respect [and] to have this broad exchange of ideas. I think the students really pick up on that, so that kind of culture does spill over to the students and, even if we're not thumping our chests and putting that in explicit lectures, I think they do pick up on that. 
For another faculty member, role-modeling took the form of performing service to the community. The professor, who teaches at a very high research institution, spoke about students seeing his television appearances through his involvement in a local planning commission, saying,

I think certainly faculty can lead by example ... I would explain that [serving on the planning commission] is part of what I felt was service to my community and that we would review plans and things like this. I think that the visibility of faculty involved with awards and commissions and whatnot is one way that we send a signal about how we, as a faculty, think is by what we do ... Being involved and by allowing our students to know that we're involved in these types of things is an important signal that we can send.

Some students at a range of institutions agreed with these statements, citing professors' behaviors as a way that they learned about ethics. However, in other instances students reported that they did not consider professors to be role models and did not believe that they had learned ethical behavior by observing them. For one student at a very high research institution, interacting with faculty did not provide examples of behavior that reflected either positive or negatively on the faculty members' ethics. This student said that faculty could be role models, but they would first have to let students see more of their behavior.

I'd say they have the potential to be [role models]. They're not necessarily doing a bad thing, but they're not doing a really good thing either.

Another student at a very high research institution echoed that sentiment, saying,

I've not really had teachers try to be role models, I guess. I feel like they don't take it as part of their job, which is fine I think.

For some students, their interactions with faculty were largely limited to time in the classroom. In these cases, students described the nature of the material discussed in class or the limited time spent with a professor as limiting the amount of behavior they observed ethical or not. One student at a very high research institution reported that it was difficult to observe the behavior of the faculty to know whether they were employing positive ethics or not, saying,

They stand in front of me three times a week for 50 minutes and talk. I mean, it's hard to get any sense of their ethical behavior.

Contributing Factor: Students observe faculty participating in unethical behavior. Although faculty like those quoted earlier in this section participated in ethical behaviors they hoped their students would learn from, students report that other faculty behaviors they observe fall at the other end of the ethics spectrum. Some of the faculty are role-modeling unethical behaviors for students that contradict the ethical behaviors they might see. For example, a professor at a very high research institution discussed a situation where students were aware of faculty behaving unethically in conducting research.

I know of a couple of faculty that have done some very questionable things with writing proposals and students learn very quickly, 'Oh, OK, here's a way around. Here's a way to get more.' And so I think the faculty have to be very careful about not sending the wrong signals in their action. 
Beyond describing the observed behavior, this faculty member states that students "learn very quickly" from seeing this type of faculty behavior. In this description, students are learning ethics from the behavior their professors' role-model; however, these behaviors are likely to contradict the messages of the ethical behaviors like those described above.

According to a student, this contradiction in messages about ethics can arise even beyond the students who witness the professor engaging in unethical behavior. Beyond simply witnessing these behaviors, students tell one another about what they have seen, spreading the potential impact of the behavior among students.

This [is] a very, very small place, and so the lore about professors-which I hear a great deal of-circulates extremely quickly. And there's certainly a sense among students about what is unfair and it's very highly developed. And I think it can't help but impact their ethical development when they think that individuals who are teaching them are being unfair.

Despite the ethical behavior that some faculty believe they are role-modeling to students, those students see other professors behaving in unethical ways. Witnessing these unethical behaviors - or hearing about them from other students who have-creates unclear messages in the education process, making it more difficult for students to learn from the positive behaviors they do witness.

Contributing Factor: Faculty approval of unethical behavior. In addition to students witnessing unethical behavior from professors, they also described witnessing professors giving approval (both implicit and explicit) of the unethical behaviors of students. In one focus group, students discussed the messages they had received from faculty specifically encouraging them to cheat on academic work if it would make the difference between failing and passing a class. One student reported hearing an extreme example of this type of behavior:

I heard a professor say in the class one day, a type of study session, and these are his exact words: 'It's better to cheat than repeat. Just don't get caught.'

Another student discussed a faculty member who encouraged students to purchase textbooks by “just going online and get the $\$ 30$ one that's made for India that they ship from overseas" rather than paying for the more expensive version of the textbook that was printed for students in the United States. The student saw this not only as encouraging unethical behavior, but also missing an opportunity to discuss factors that lead to the different prices and inform the ethical decision. The student said:

I feel like that's a critical thing where this professor is you know, endorsing that sort of behavior that's obviously not ethical and yes, a lot of kids do buy the soft cover versions, which are not intended for U.S. use. However I don't think it's ethical, you know, the teacher shouldn't say, you should buy this one because it's cheaper, or encourage that practice. He should have a discussion and say, 'These are cheaper, here's why they're cheaper.'

In other cases the approval students believed faculty to be giving for unethical behavior was less explicit. One student described the belief that the amount of work that engineering 
students are expected to do is tantamount to an implicit message that unethical behaviorcheating on coursework - is acceptable when completing schoolwork.

'[Students think] I must be supposed to use whatever resources are at my disposal to get it done, otherwise I'd never get it done.' It's almost like the ancient Spartans not feeding their children and encouraging them to steal food to engender stealth. The ... a lot of the students [think], 'I must be supposed to go out and find everything I can possibly get my hands on to get this done. Otherwise, they wouldn't give me 10 hours [of work] a night.'

Although faculty and administrators describe their role-modeling of ethical behavior as an important part of ethics education, students do not report perceiving it in the same way. Despite the intentions of at least some faculty to role-model positive ethical behavior for students, other faculty members are seen as demonstrating unethical behavior themselves and encouraging that behavior in students. Seeing this unethical behavior and encouragement toward it in the same academic environment overshadows what the positive role model faculty are trying to accomplish as the larger environment contradicts these efforts.

\section{DISCUSSION AND IMPLICATIONS}

We used data from faculty and student focus groups and administrator interviews from a representative sample of 18 engineering programs to examine the discrepancies between the perceptions of educators and students in regards to curricular ethics education. Further, we identified aspects of the educational environment that contribute to those discrepancies. Results of this study support the hypothesis that significant differences do exist between the perceptions of faculty, administrators, and students in regards to ethics education. We found that faculty and administrators often describe ethics education as comprising a balance between knowledge of ethical codes of conduct and understandings of ethical rights and wrongs with a more nuanced, complex understanding of ethical dilemmas that accounted for a preponderance of "gray area." Students, however, reported their ethics education was almost entirely the former with little to none of the latter.

We also found that faculty and administrators described the role-modeling of positive ethical behavior as a component of ethics education, but students in many cases did not perceive these role-modeled behaviors. Further results demonstrated that other aspects of the educational environment in which students learn ethics can contribute to these discrepancies. Specifically, a singular focus on black-and-white questions of academic integrity and the negative personal consequences of academic cheating overshadow more nuanced approaches to ethics education. Additionally, unethical behaviors by faculty and the explicit and implicit approval and encouragement of student unethical behavior overshadow the positive ethical behavior that some faculty model for students.

These results make it clear that when it comes to ethics education, student outcomes are not simply a product of their classroom experiences, but also from their experiences with faculty and other students in the larger educational environment. This conclusion and the study's results lead to multiple suggestions for engineering educators:

- use the results to provide direction for in-class ethics education;

- include student perspectives when planning and evaluating ethics education efforts;

- consider the ethics education outcomes as being influenced by the educational environment in addition to classroom instruction; 
- and incorporate research and assessment of the effect of the educational environment when designing and assessing education for other outcomes.

These results provide direction for engineering instructors when designing formal ethics education for undergraduate engineering students. It is essential that faculty are aware of the students' experiences and interactions that are working against the instruction they are receiving in formal curriculum. For example, if institutions place a strong emphasis on academic integrity and the punishment students will receive if they are caught cheating on academic work, faculty teaching ethics can explicitly present academic integrity as connected to professional ethics. Academic integrity rules are similar to the types of laws and industry rules and regulations that professional engineers must follow to avoid punishment, but they do not represent the broad range of complex ethical dilemmas students will encounter as professional engineers. This focus on academic integrity can create a starting point for discussions in the classroom about different types of ethical dilemmas and decisions, allowing this important focus on academic integrity to be a component of a broader discussion of ethics rather than allowing it to crowd out these other important discussions.

Faculty can also be more purposeful about role-modeling positive ethical behavior for students. If, as the results presented here suggest, many students are largely unaware of these positive behaviors engaged in by their faculty, faculty should work to explicitly direct students' attention to these behaviors. Even when teaching topics other than ethics, faculty can draw on their own experiences describing ethical dilemmas they encountered and the positive ethical behaviors enacted when encountering the dilemma. This will allow them to better draw attention to the ethical things that they do that students may be unaware of. Secondly, faculty can acknowledge the unethical behavior of other faculty and the messages that students are receiving approving of and encouraging unethical behavior. Without naming names or discussing the specific situations or actions of colleagues, faculty can address unethical behavior they have witnessed in their professional experiences or messages they believe students are receiving. Acknowledging these unethical behaviors and drawing explicit comparisons to the positive behaviors that other faculty are role-modeling will both draw attention to the negative behavior and keep it from overshadowing the positive behavior.

Beyond these specific recommendations for ethics instruction, the results of this study also provide suggestions for designing and evaluating ethics education. With the importance of ethics education to the field of professional engineering and the accreditation of academic engineering programs, understanding how students perceive their experiences is an important step in assessing the effectiveness of ethics education in academic programs. In the context of the results of this study, it is possible-even likely-that faculty members' and administrators' ideas about their programs' curricular ethics instruction do not match the experiences of their students. It would be virtually impossible to understand the effectiveness of these curricular efforts without knowing how students perceive their experiences.

If these differences between perceptions of students and faculty exist, as this study suggests, it is vital for faculty and administrators to look beyond classroom instruction to understand why. Results of this study point both to specific actions of faculty - in their own ethical behavior and encouraging that behavior in students - and specific emphases of discussions of ethics that overshadow and crowd out the type of ethics education that faculty feel they provide and students crave. To understand how students are learning about ethics, these out-of-class experiences and interactions must be considered as contributing to students education and their effects be understood. 
Finally, it is likely that similar types of discrepancies exist in other types of instruction (besides ethics education), particularly in non-technical areas in which outcomes have traditionally been more difficult to assess. Beyond ethics, other ABET program outcomes where this model and approach could prove useful include working in multidisciplinary teams (outcome E), communicating effectively (outcome $\mathrm{G}$ ), engaging in lifelong learning (outcome I), and understanding the impact of engineering in global, economic, environmental, and social contexts (outcome H). A careful examination of the perceptions of students about educational efforts for these outcomes and how these perceptions do or do not match those of faculty and administrators can provide an important foundation to the assessment of the success of curricular efforts. Further, educators should look beyond classroom education to understand how aspects of the educational environment might be contributing to those differences for these other outcomes.

\section{ACKNOWLEDGMENTS}

This work was supported in part by grants from the National Science Foundation (EEC\# 0647460, 0647532, and 0647929). The views expressed represent those of the authors and not necessarily those of the National Science Foundation.

\section{REFERENCES}

ABET (2010). Criteria for accrediting engineering programs: Effective for evaluations during the 2010-2011 accreditation cycle. Retrieved from http://www.abet.org

Astin, A. W. (1970a). The methodology of research on college impact (Part I). Sociology of Education, 43(3), 223-254.

Astin, A. W. (1970b). The methodology of research on college impact (Part II). Sociology of Education, 43(4), 437-450.

Astin, A. W. (1993). Assessment for excellence: The philosophy and practice of assessment and evaluation in higher education. Phoenix, AZ: The Oryx Press.

Bielby, R., Harding, T. S., Finelli, C.J., Carpenter, D. D., Sutkus, J. A., Holsapple, M. A., Burt, B. A., \& Ra, E. (2011). Impact of different curricular approaches to ethics education on ethical reasoning ability. Proceedings of the 2011 ASEE Annual Conference E Exposition, Vancouver, Canada.

Burt, B. A., Carpenter, D. D., Finelli, C. J., Harding, T. S., Sutkus, J. A., Holsapple, M. A., Bielby, R., \& Ra, E. (2011). Outcomes of engaging engineering undergraduates in cocurricular experiences. Proceedings of the 2011 ASEE Annual Conference E' Exposition, Vancouver, Canada.

Carnegie Foundation for the Advancement of Teaching. (2009). The Carnegie classifications of institutions of higher education. Retrieved from http://www.carnegiefoundation.org/classifications/

Colby, A., \& Sullivan, W. M. (2008). Ethics teaching in undergraduate engineering education. Journal of Engineering Education, 97(3), 327-338.

Corbin, J., \& Strauss, A. (2008). The basics of qualitative research: Techniques and procedures for developing grounded theory (2nd Ed.). Thousand Oaks, CA: Sage Publications. 
Eagen, M. K., \& Jaeger, A. J. (2008). Closing the gate: Part-time faculty instruction in gatekeeper courses and first-year persistence. New Directions for Teaching and Learning, 2008(115), 39-54.

Falls, M. D. (2009). Psychological sense of community and retention: Rethinking the first-year experience of students in STEM (Doctoral dissertation). Retrieved from http://etd.fcla.edu/ CF/CFE0002841/DagleyFalls_Melissa_A_200912_EdD.pdf

Finelli, C. J., Harding, T. S., Carpenter, D. D., \& Mayhew, M. J. (2007). Academic integrity among engineering undergraduates: Seven years of research by the $\mathrm{E}^{3}$ Team. Proceedings of the 2007 ASEE Annual Conference E' Exposition, Honolulu, HI.

Finelli, C. J., Holsapple, M. A., Ra, E., Bielby, R. M., Burt, B .A., Carpenter . . Sutkus, J. A. (In Press). Journal of Engineering Education.

Fritschner, L.M. (2000). Inside the undergraduate college classroom: Faculty and students differ on the meaning of student participation. Journal of Higher Education, 71(3), 342-362.

Gill, D., Heins, M., \& Jones, P.B. (1984). Perceptions of medical school faculty members and students on clinical clerkship feedback. Journal of Medical Education, 59(11), 856-864.

Godfrey, E., \& Parker, L. (2010). Mapping the cultural landscape in engineering education. Journal of Engineering Education, 99(1), 5-22.

Goldstein, G. S., \& Benassi, V.A. (2006). Students' and instructors' beliefs about excellent lecturers, and discussion leaders. Research in Higher Education, 47(6), 685-707.

Harding, T. S., Carpenter, D. D., Finelli, C. J., \& Passow, H. J. (2004). Does academic dishonesty relate to unethical behavior in professional practice? An exploratory study. Science and Engineering Ethics, 10(2), 311-324.

Harding, T. S., Sutkus, J. A., Finelli, C. J., \& Carpenter, D. D. (2009). Engineering culture and the ethical development of undergraduate students. Proceedings of the 2009 International Research in Engineering Education Symposium, Palm Cove, Queensland, Australia.

Haws, D. R. (2001). Ethics instruction in engineering education: A (mini) meta-analysis. Journal of Engineering Education, 90(2), 223-229.

Holsapple, M. A., Sutkus, J. A., Carpenter, D. D., Finelli, C. J., Burt, B. A., Harding, T. S., \& Bielby, R. (2011). We can't get no satisfaction!: The relationship between students' ethical reasoning and their satisfaction with engineering ethics education. Proceedings of the 2011 ASEE Annual Conference E' Exposition, Vancouver, Canada.

Holsapple, M. A., Finelli, C. J., Carpenter, D. D., Harding, T. S., \& Sutkus, J. A. (2009). Work in progress - A mixed-methods approach to developing an instrument measuring engineering students' positive ethical behavior. Proceedings of the 39th IEEE/ASEE Frontiers in Education Conference, San Antonio, TX.

Jaeger, A. J., \& Hinz, D. (2008). The effects of part-time faculty on first semester freshman retention: A predictive model using logistic regression. Journal of College Student Retention, 10(3), 265-286.

Lincoln, T. D. (2009). The seminary experience: Conceptual worlds of first-career and second-career seminarians. (Unpublished doctoral dissertation). University of Texas, Austin, TX.

Lovik, E. G., \& Volkwein, J. F. (2010). The impact of organizational features and student experiences on spiritual development during the first year of college. Paper presented at the Annual Conference of the Association for the Study of Higher Education (ASHE), Indianapolis, IN. 
MacLellan, E. (2001). Assessment for learning: The differing perceptions of tutors and students. Assessment and Evaluation in Higher Education, 26(4), 307-318.

McGinn, R. E. (2003). 'Mind the gaps': An empirical approach to engineering ethics, 19972001. Science and Engineering Ethics, 9(4), 517-542.

Merriam, S. B. (1998). Qualitative research and case study applications in education. San Francisco, CA: Jossey-Bass.

Miron, M. (1988). Students' evaluation and instructors' self-evaluation of university instruction. Higher Education, 17(2), 175-181.

Murphy, C. (2010). Residential learning outcomes: Analysis using the college student experiences questionnaire at a large public research university. (Unpublished doctoral dissertation). University of South Florida, Tampa, FL.

Nasser, F., \& Fresko, B. (2006). Predicting student ratings: The relationship between actual student ratings and instructors' predictions. Assessment and Evaluation in Higher Education, 31(1), 1-18.

National Academy of Engineering. (2003). Emerging technologies and ethical issues in engineering. Washington, DC: National Academies Press.

National Academy of Engineering. (2004). The engineer of 2020: Visions of engineering in the new century. Washington, DC: National Academies Press.

Newberry, B. (2004). The dilemma of ethics in engineering education. Science and Engineering Ethics, 10(2), 343-351.

Patton, M. Q. (2002). Qualitative research and evaluation methods (3rd Ed), Thousand Oaks, CA: Sage Publications.

Reason, R. D. (2009). An examination of persistence research through the lens of a comprehensive conceptual framework. Journal of College Student Development, 50(6), 659-682.

Reason, R. D., Cox, B. E., Quaye, B.R.L., \& Terenzini, P. T. (2010). Faculty and institutional factors that promote student encounters with difference in first-year courses. Review of Higher Education, 33(3), 391-414.

Reason, R. D., Terenzini, P. T., \& Domingo, R. J. (2007). Developing social and personal competence in the first year of college. The Review of Higher Education, 30(3), 271-299.

Reason, R. D., Terenzini, P. T., \& Domingo, R. J. (2006). First things first: Developing academic competence in the first year of college. Research in Higher Education, 47(2), 149-175.

Sheppard, S. D., Macatangay, K., Colby, A., \& Sullivan, W. M. (2009). Educating engineers: Designing for the future of the field. San Francisco, CA: Jossey-Bass.

Sutkus, J. A., Carpenter, D. D., Finelli, C. J., \& Harding, T. S. (2008). Work in progress: Building the Survey of Engineering Ethical Development (SEED) instrument. Proceedings of the 38th Frontiers in Education Conference, Sarasota Springs, NY.

Terenzini, P. T., \& Reason, R. D. (2005,). Parsing the first year of college: Rethinking the effects of college on students. Paper presented at the Annual Conference of the Association for the Study of Higher Education, Philadelphia, PA.

Turns, J., Eliot, M., Neal, R., \& Linse, A. (2007). Investigating the teaching concerns of engineering educators. Journal of Engineering Education, 96(4), 295-308.

Wachtel, H. K. (1998). Student evaluation of college teaching effectiveness: A brief review. Assessment and Evaluation in Higher Education 23(2), 191-211. 


\section{AUTHORS}

Matthew A. Holsapple is a doctoral candidate in the Center for the Study of Higher and Postsecondary Education, University of Michigan, 610 E. University Ave., Ann Arbor, MI, 48109; mapple@umich.edu.

Donald D. Carpenter is director of Assessment and associate professor of Civil Engineering at Lawrence Technological University, 21000 W. Ten Mile Road, Southfield, MI, 48075; carpenter@1tu.edu.

Janel A. Sutkus is director of Institutional Research and Analysis, Carnegie Mellon University, 5000 Forbes Avenue, Pittsburgh, PA, 15213; jsutkus@cmu.edu.

Cynthia J. Finelli is director of the Center for Research on Learning and Teaching in Engineering and research associate professor of Engineering Education, University of Michigan, 2609 Draper Drive, Ann Arbor, MI 48109; cfinelli@umich.edu.

Trevor S. Harding is department chair and professor of Materials Engineering, California Polytechnic State University, 1 Grand Ave., San Luis Obispo, CA, 93407; tharding@calpoly.edu. 